\title{
STUDY ON THE CHARACTERISTICS AND MECHANISM OF ETHNIC TOURISM COMMUNITY CONTRADICTION
}

\author{
Congyuan Li \\ City College, Kunming University of Science and technology, P.R.China
}

\begin{abstract}
In China, with the development of tourism in the resources of ethnic culture and natural landscape has achieved great results. With the development of tourism in ethnic regions, the issues about the stakeholders of the ethnic minority areas are more outstanding, some disputes take place in the ethnic minority areas around the distribution, and the disputes related to the tourism in ethnic regions is increasing. As the growth of disputes are getting intense, some disputes even lead to conflict, and the contradictions of ethnic tourism communities are visible. How to make the sustainable development of tourism in ethnic regions activities? That not only relates to the satisfy demands for tourists' tourism but also relates to the beneficial development of society, economy and culture in ethnic minority areas.
\end{abstract}

Key word: Ethnic tourism community; Stakeholder; Contradiction; Action mechanism

\section{JEL code: 0210}

\section{Introduction}

In recent years, with the development of tourism in the resources of ethnic culture and natural landscape has made great achievements, the tourist trips and tourism income of China's ethnic minority areas continuously rapid growth. On the provincial level, give an example for Tibetan autonomous region, according to the tourism development committee of Tibet. In 2016, the tourists of Tibet receives more than 23 million from both domestic area and abroad, an increase of $14.8 \%$ on last year's same period; Tibet autonomous region to achieve tourism revenue of 33 billion 75 million Yuan, an increase of $17.3 \%$ on last year's same period. In 2016, the tourism revenue in the autonomous region of Tibet was equivalent to $28.81 \%$ of GDP in Tibet autonomous region (see http://www.xizang.gov.cn, 2017). In the prefecture level autonomous prefecture, website the of tourism development Committee of Xishuangbanna Dai Autonomous Prefecture published on January 2016, the cumulative total domestic and foreign tourists is up to 74 million 615 thousand and 500 person time during 12th FiveYear period, the cumulative increase of 2.42 times than during the 11th Five-Year period (30 million 721 thousand and 600 times); they forecast that the total tourism income will up to 91 billion 117 million Yuan, that is 3.71 times than during the 11th Five-Year period (24 billion 510 million Yuan)(see http://www.xsbnly.com, 2016).Tourism which rely on the natural landscape resources and ethnic culture has been considered to promote local economic development, and promote the transformation of rural society, and promote community out of poverty and an effective approach to realize leap- 
forward development in ethnic regions.(see Li et al, 2012)

However, with the deepening of tourism in ethnic regions, the diversity of tourism activities stakeholders and the diversification of interests in ethnic minority areas, and so on, they made into complex networks, the issues about the stakeholders of the ethnic minority areas are more outstanding, some disputes take place in the ethnic minority areas around the distribution, and the disputes related to the tourism in ethnic regions is increasing. As the dispute grows more intense, some disputes even lead to conflict (see Wood R E, 1985), and the contradictions of ethnic tourism communities are increasingly visible.

\section{The analysis of ethnic tourism community contradiction}

\section{1 ethnic tourism community types of contradictions}

The contradiction of the ethnic tourism community exists in the ethnic society. The ethnic society is based on the common geography and the close ties of daily life of the members of the ethnic society. The core production is the tourism reception activities in the ethnic society. The contradiction of the ethnic tourism community are mutually compatible, frictional or mutually incompatible phenomena and relations. According to different classification standards, the contradiction of the ethnic tourism community can be divided into the following types: according to the space of the conflicts, the contradiction of ethnic tourism community can be divided into external and internal contradictions. According to the main body of conflict, the contradiction between the ethnic tourist communities can be divided into individual contradictions and group contradictions. According to the reasons of contradiction, the contradictions of the ethnic tourism community can be divided into economic, political, social and cultural contradictions. According to the time of conflict, the contradictions of the ethnic tourism community can be divided into existing contradictions and potential contradictions.

\subsection{The contradictory characteristics of ethnic tourism community}

The contradictions of ethnic tourism community have the following characteristics: First, ethnic tourism community contradictions type is various, and community internal economy causes of conflict is still dominant. Second, the main body of ethnic tourism community contradictions is overlapping sexual characteristics. For example, tourists are the demand of ethnic community tourism products and buyers, and are the beneficiary of ethnic tourism activities; Community residents are not only the ethnic tourism activities of participants and server, but also distributors and mutual business interests. Third, ethnic tourism community the root causes of contradictions presents the characteristics of diversity and complexity. An ethnic tourism community contradiction is often caused by a variety of reasons, and between a variety of reasons and mutual crisscross is very complex. At the same time, due to the tourism activities 
involving food, accommodation, transportation, traveling, shopping, entertainment and so on each aspect, has the characteristics of complexity, wide range, the correlation between big, complicated by ethnic tourism community social relations. Fourth, the community contradiction in ethnic tourism is evolving. Under the condition of social change, community residents of ethnic tourism also changes with the change of the external factors. After the introduction of tourists from all parts of the community residents to society, to the outside world, self-awareness, and constantly improve, constantly improving its appeal will be in this changing in the process. When changing demands cannot get timely guidance and meet is that contradiction and conflict arise. Fifth, ethnic tourism community contradictions and social capital considerations are closely related. Community residents living environment and community are important tourist attractions that based on the daily life of the natural scenery and ecological culture create economic value, become a kind of social capital. However, for a long time, the community of ethnic tourism value of social capital is often overlooked because of the complexity of the social capital has a value determined characteristic. As ethnic tourism community residents thought the gradual awakening of commodity economy, property, rights protection consciousness gradually strengthened a series of problems, the community of ethnic tourism highlighted contradictions and conflicts, some ethnic tourism community even so sparked public crisis.

\section{The causes of ethnic tourism community contradictions and action mechanism}

\subsection{The analysis of the causes of ethnic tourism community contradictions}

\subsubsection{Economic factors}

Economy is the main reason of ethnic tourism community contradiction and conflict caused by the difference of economic interests (see Gursoy, Rutherford, 2004). It is the inevitable outcome of the economic exchange under specific social conditions. In the ethnic tourism community, the main body mainly manifested as the owner groups of the production goods and non owner groups of the production goods; group of management, operator and common laborers; community managers and community residents, the consumers of tourism and the providers of tourism. In the development of productive forces need to break through the old way of economy, the new and old economic structure, and supporters of system can produce conflict and contradiction. When the old economic structure and system tends to collapse, and the new economic structure and system has not yet been replaced, the corresponding constraints means such as policies, rules, regulations and mechanism also is relatively weak, makes market economy appeared different degree of chaos, the chaos also provides conditions for the emergence of the constraint and conflict. Under compared with community of external economic demonstration, the pursuit of interests of people are generated by the trigger and strengthening. When community economy structure adjustment can't faster than people expect growth, can form the interests of the social main body expectations and the reality condition of imbalance. Under certain conditions, that will lead to 
economic contradictions and conflicts. These contradictions in that part of the social main body to the social order, the economic order maintenance lack the necessary subjective basis; Some social main body beyond the requirements of the economic order, to evade or through the violation of laws and regulations in an effort to seek illegitimate interests, resulting in economic contradictions and conflicts between the beneficiaries and victims. At the same time, the changing structure of the economic development and economic rights and interests of the economy is bound to strengthen subject consciousness, arouse the social main body strong attention on their own interests. The strong sense of interests often with self-interest tendency, can make the interest disputes between economic subjects, their interests desire slightly differences are likely to become an economic disputes. Due to a strong sense of interest, and even produce economic subject in the pursuit of self-interest maximum value when the phenomenon of damage the interests of others, difficult to eliminate automatically, generating economic contradictions and conflicts. Performance in ethnic tourism in the community, the most obvious is the social vulnerable groups' capital value is ignored. In addition, when a sharp economic change actually occurs, will inevitably produce economic subject can adapt to new economic life; many economic main body to produce the feeling of at a loss is inevitable. The conflicts and contradictions of ethnic tourism community is sparked because this adaptation and vacant in the community economy.

\subsubsection{Political factors}

Political contradiction will inevitably produce when violent social change. Political contradiction ethnic tourism community has close connection with social change. At present, Chinese society is in transition, and the transitions of the social and economic are emerging. The change of economy must touch the interests of some social groups, also can produce new interests. Social member or group requires resolved through political means when these interests can't through economic means to achieve satisfied (see Tosun C, 2000; Scheyvens, 1999，2002; Sofield, 2003). Political conflicts and disputes emerge. The changes of the economic cause and aggravate the contradiction between social groups and conflicting interests. People's democracy consciousness will strongly continuously in the social change, making points on the political situation, criticism, and evaluation begins to be members of society or group considered as citizen rights. At the same time, people think that, with their own ideas to influence the political process or directly involved in the political process is a kind of civil liability. These appear in social change prompted more and more social members produce the requirements of political participation (see Mitchell, Reid, 2001; Hampton, 2005; Nunkoo, Ramkissoon, 2011). Even part in social life there is hope frustrated members of society through the political participation to the government notice their interests and requirements. At the same time, the social change of the new social forces or social groups through political participation to obtain corresponding political status (see Nunkoo, Ramkissoon, 2011). Members of the social values change with Economic changing, the social members call for the government officials and civil servants with a new value concept and judgment. However, in the transformation period, the speed 
of social citizen political participation is often faster than the speed of social allows citizens' political participation. Information asymmetry, vulnerable groups rights are not respected and the awakening of consciousness and individual consciousness enhancement, the increase of legal knowledge interweave, combined with the particularity of ethnic tourist attractions in the community, and with money, only a single solution has been unable to deal with various complex problems of social transition, cause the political conflict and contradiction in the ethnic tourism community.

\subsubsection{Social and cultural psychological factors}

In the period of social transition, social change promotes the progress of the society, at the same time social change also can bring a variety of social problems. The old organizational structure, the resilience lack of political system and self-adjusting mechanism and so on, will produce a series of problems. Some change will cause the original social issues become more prominent and intensified. Under the impetus of the social change, society increasingly open to the trend of development, the progress of the society will inevitably lead to cultural changes. Social change has brought collision between new culture and old culture, between local culture and foreign culture, the new culture adapting to and guiding the social development will be retained, closed and exclusive culture are bound to fall out during the development of the society; the culture adapting to the development of the society and the excellent culture will replace the old culture backward and not adapting to the development of the society. In the process of social change, both new and old culture, or native culture and foreign culture, there are mutually absorb its reasonable composition, merged into the possibility of a new culture. This cultural change process will inevitably bring various social problems, psychological problems, these problems related to interweave, lead to travel community ethnic social and cultural psychological contradiction and conflict.

\subsection{The main Contradictions mechanism of ethnic tourism community}

Community residents are the core subject of ethnic tourism community. The contradiction of ethnic tourism community is closely connected with community residents' perception and attitude towards tourism, and is closely connected with the interests of the community residents' demands ethnic tourism. So to speak, the contradiction of ethnic tourism community is the result of the community residents' demands change. Based on the theory of product life cycle, the development of the ethnic tourism community can be divided into tourism products input stage, growth stage, mature tourism products, tourism products, tourism products, and so on. Because each stage has different social conditions during ethnic community tourism activities, and the different content of economic exchange, and the demands community of each stakeholder group are also different. These differences make the contradictions of ethnic community tourism evolve and change, and present different characteristics in the different stages of tourism activities. 
3.2.1 The characteristics and mechanism of the contradiction of Ethnic tourism community in the period of tourism product investment

in China, most ethnic regions belong to economic underdeveloped regions, and the social and economic development is relatively lagging, and mostly located in remote areas, is located in the country, traffic relatively closed. In tourism activities has just entered the ethnic community, most of the ethnic community is mainly given priority to agricultural industry, economic income is not high, the community condition is bad, most of the trip is poorer, living environment urgent to be improved. The local government actively introduce tourism development enterprise, hope to increase residents income through tourism development, make the local residents out of poverty; Enterprise hope to receive economic returns through to the development of ethnic tourism community tourism; Community residents hope to receive the improvement of the living environment and the improvement of economic income, and the expectations of developing tourism are very high, everyone is actively preparing for, scrambling to requirements to participate in tourism in various ways, to greet the arrival of a new life. Tourists hope to get new travel experience, receive tourist satisfaction. Suggested budgeting in tourism, each stakeholder group of ethnic tourism community has positive expectations to travel. The mechanism of the contradiction of Ethnic tourism community in the period of tourism product investment is shown in figure 1.

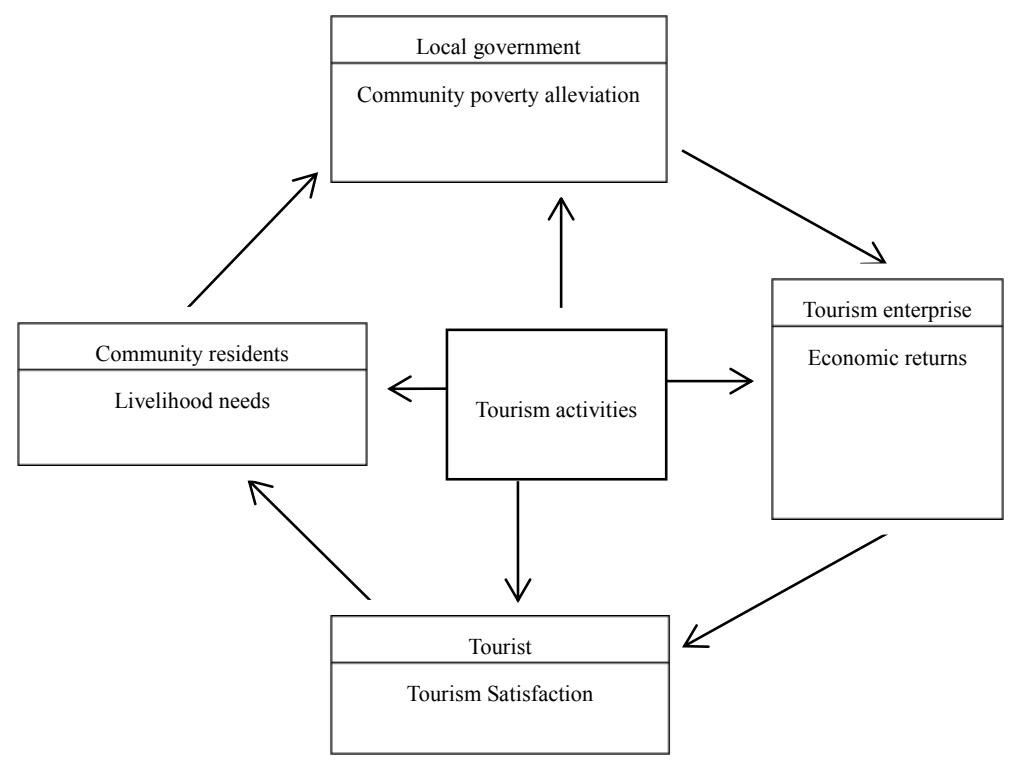

Fig.1 The mechanism of the contradiction of Ethnic tourism community in the period of tourism product investment

During the period of tourism product investment, the community residents as the main body, the group consciousness of the social members of community residents is greater than the individual consciousness, their demands for a living demand is greater than the political demand. The contradiction in this period mainly manifested as the contradictions because of the community both inside and outside the economic interests 
of the differences and the contradictions caused by cultural differences between the old and the new. These contradictions are moderate, and promote the development of the ethnic tourism community.

3.2.2 The characteristics and mechanism of the contradiction of Ethnic tourism community in the period of tourism product developing

During tourism product developing, due to the further involvement in tourism activities, ethnic tourism community has entered a rapid development period. At this stage, the stakeholder groups of ethnic tourism community cooperate with each other. The local government to continue to provide support for tourism enterprises on tourism development and coordination; In order to obtain more economic profit, tourism enterprises constantly promoting development efforts; the community residents involved in tourism activities gained tangible benefits in the ethnic tourism community, community environment was improved; Tourists have a certain knowledge of ethnic tourism community, won a certain travel experience, obtained the certain tourist satisfaction. At this stage, the each stakeholder group of ethnic tourism community made a certain profits. However, due to the change of economic communication content, the change of the social condition, the broaden horizons of people, especially economic interests distribution problems in the process, the negative influences of tourism activities in the ethnic tourism community appeared gradually, the community consciousness of commodity economy and simplicity of traditional ethnic consciousness collide, group consciousness of collision with the individual consciousness, the community property, rights protection consciousness gradually strengthened. The mechanism of the tourism product developing ethnic tourism community contradictions function is shown in figure 2 .

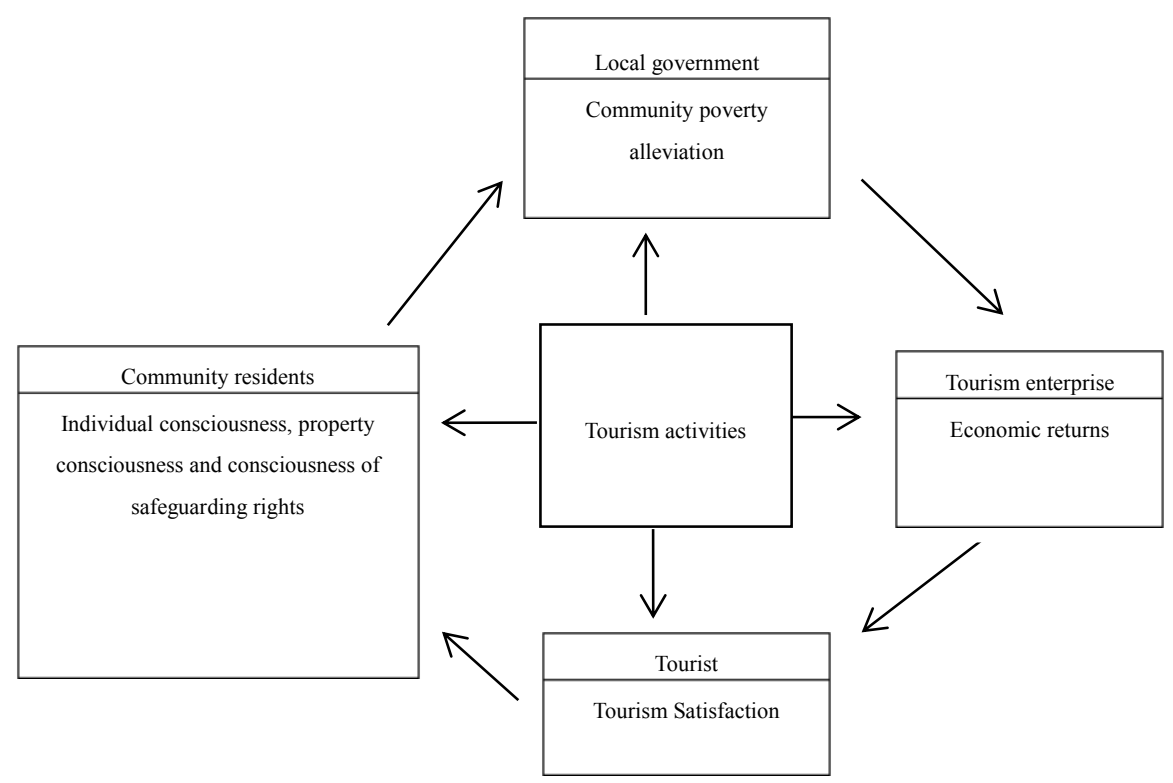

Fig.2The mechanism of the tourism product developing ethnic tourism community contradictions function 
The contradiction of this period mainly manifested as the contradictions because of the economic interests of the community internal difference, the difference of community participation, the cultural differences between the old and the new, old and new system change, and social psychological gap. If these contradictions get effective relief, these contradictions will be to promote community development of ethnic tourism motivation. These contradictions without the effective communication will damage the community of ethnic tourism social order; hinder the ethnic tourism community's social and economic development.

3.2.3 The characteristics and mechanism of the contradiction of Ethnic tourism community in the period of tourism product mature

During tourism products mature, tourism activities tend to be stable, the various rules and regulations and operating mechanism is improved in ethnic tourism community. After running-in, the each stakeholder groups of ethnic tourism community cooperate and achieve a certain tacit understanding. After the contradiction during of tourism growth got the evacuation, ethnic tourism community got good development. The local government well acquainted to provide support and services for the tourists, community residents and tourism enterprises; Tourism enterprises can straighten out relationship of all aspects, get stable economic profits; Ethnic tourist community residents obtain economic benefits, further improve community environment; Tourists have conditions to make full understanding of the ethnic tourism community, full of yearning about the ethnic tourism community, get the tourism satisfaction after the travel experience. The mechanism of the contradiction of Ethnic tourism community in the period of tourism product mature is shown in figure 3 .

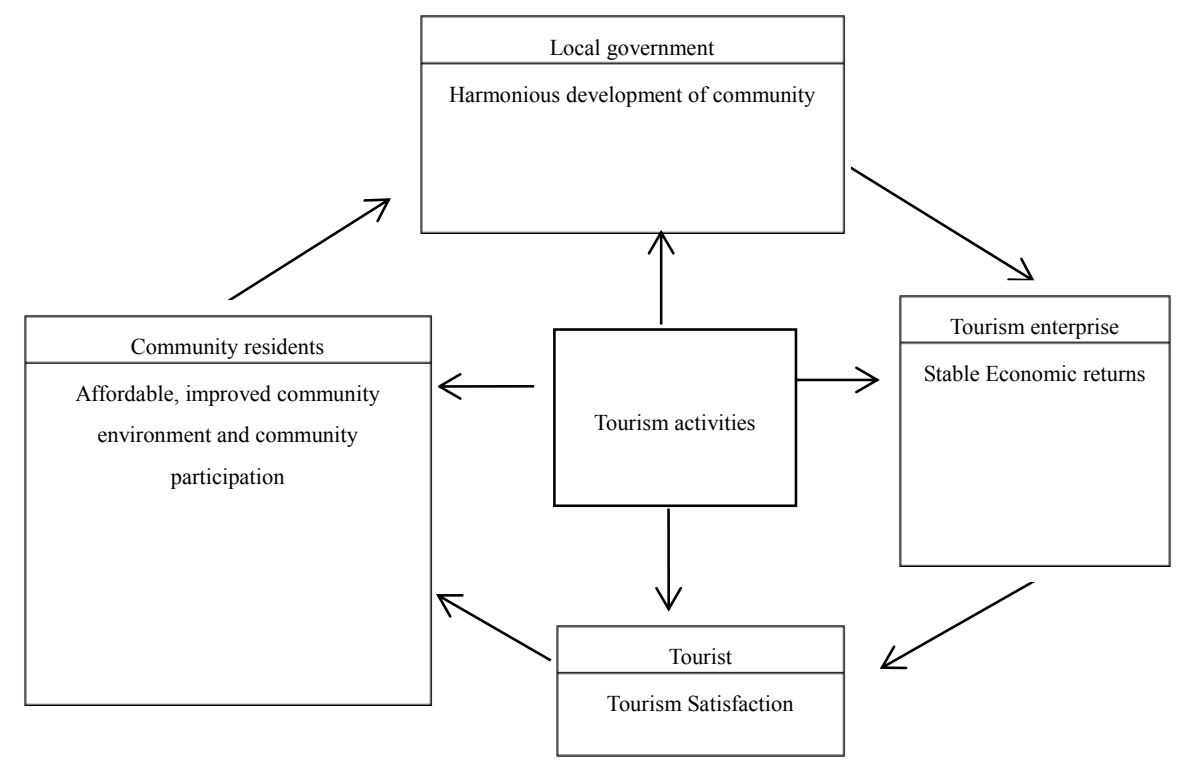

Fig.3 The mechanism of the contradiction of Ethnic tourism community in the period of tourism product mature

At this stage, the each stakeholder group of ethnic tourism community makes a great 
profit, and the internal interest relations between various interest groups achieve the balance in ethnic tourism community. However, tourism activities bring the overcrowded, external social conditions changed, the emergence of new economic exchanges, individual negligence in the process of system implementation, and so on, that brief balance will be broken, disequilibrium of the interests relationship will appear, and produces the new contradiction. Thanks to the previous good operating base, new contradictions can get timely relief, the interest relationship various interest groups balance again in ethnic tourism community. In tourism development stage, equilibrium and disequilibrium coexist. The contradiction of this period mainly manifested as for differences due to the economic interests and social contradictions caused by psychological reasons.

3.2.4 The characteristics and mechanism of the contradiction of Ethnic tourism community in the period of tourism product investment recession

During recession, the tourism products of ethnic tourism community are aging, market vitality is reduced, the new tourism substitute appear, the interest of tourists transfer, the interests of ethnic tourism community's related groups due to tourism activities is reduced. New products, new economic structure, the new system, new economic structure, a new culture be vividly portrayed. The emergence of new products, new economic structure can lead to the change of system. The old economic structure and system tends to collapse, and there has not yet been replaced by the new economic structure and system, the corresponding constraints means such as policies, rules, regulations and mechanism also is relatively weak, that makes market economy appeared different degree of chaos, the chaos of the residents also provides conditions for the emergence of the contradiction and conflict. The new social forces and group that is produced by social change want to get the corresponding political status through the political participation. The contradictions between old and new social forces or groups appear too. At the same time, the new culture adapting to the social development appear, there are contradiction and conflicts between the old culture and the new culture adapting to and guiding the development of the society. Old and new culture mutually absorb its reasonable composition, the thing of old culture that don't adapt to the development of the society will be eliminated, adapt to and guide the development of the society culture will be retained, complement each other in the old and new culture will make into a new social culture. The mechanism of the contradiction of Ethnic tourism community in the period of tourism product investment recession is shown in figure 4 . 


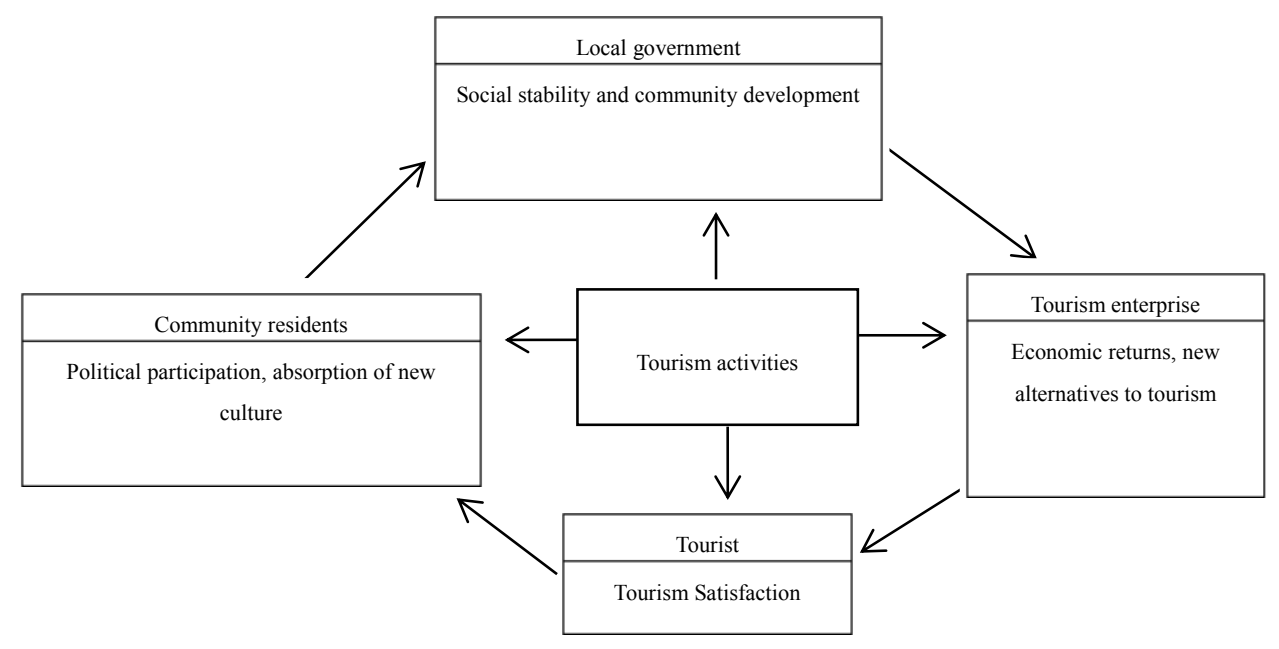

Fig.4 The mechanism of the contradiction of Ethnic tourism community in the period of tourism product investment recession

The contradictions of ethnic tourism community in this period are relatively complex. The contradictions triggered by economic factors, political factors and social psychological factors are intertwined.

\section{Conclusion}

There are mutual influence and interaction and interdependent relationships among the major interest groups of ethnic tourism community. Due to different social conditions and economic exchange content are different, the demands of each stakeholder group of ethnic tourism community during different tourist activity stage are also different, these differences make the contradictions of ethnic tourism community to evolve and change, make dynamics contradictions of ethnic tourism community to be with solid sex contradictions of ethnic tourism community, balanced and unbalanced coexistence. According to the characteristics of different tourism activities stages, rationally and dynamically treating the social contradictions of ethnic tourism community will promote the harmonious development of tourism of ethnic community.

\section{References}

http://www.xizang.gov.cn/xzly/lydt/201703/t20170310_122493.html, 2017-3-10

http://www.xsbnly.com/xsbnly/jb/61282.jhtml, 2016-01-14

Li et al. Study on the Operation Mechanism in Tourism Activities Based on Theory of Stakeholders, 2012 international conference on management science \& engineering 
19th annual conference roceedings.2012:823-832, 2012.

Wood R E. Ethnic tourism, the state and cultural change in Southeast Asia. Annals of Tourism Research, 1985,11(3): 353-374.

Gursoy D, Rutherford D G. Host attitudes toward tourism: An improved structural model. Annals of Tourism Research, 2004,31(3): 495-516.

Tosun C, Limits to Community Participation in the Tourism Development Process in Developing Countries. Tourism Management, 2000,21(6): 613-633.

Scheyvens R, Ecotourism and the Empowerment of Local Communities. Tourism Management, 1999,2(20): 245-249.

Scheyvens R, Tourism for Development: Empowering Communities. Harlow: Pearson Education, 2002.

Sofield T, Empowerment for Sustainable Tourism Development .Oxford: Pergamon, 2003.

Sofield T, Empowerment for Sustainable Tourism Development .Oxford: Pergamon, 2003.

Mitchell R E, Reid D G. Community Integration: Island Tourism in Peru. Annals of Tourism Research, 2001,28(1): 113-139.

Hampton M P, Heritage, Local Communities and Economic Development. Annals of Tourism Research, 2005,32(3): 735-759.

Nunkoo R, Ramkissoon H. Developing a Community Support Model for Tourism. Annals of Tourism Research, 2011,38(3): 964-988. 